DOI: $10.47456 / k r k r . v 1 i 9.31957$

\title{
Conexão Sustentável: um projeto de fomento à educação ambiental
}

Sustainable Connection: a project of promotion of environmental education

Danilo Garufe Gomes

Ana Maria Gimenes Corrêa Calil

Antonio Rodolfo Souza da Silva Juliana Marcondes Bussolotti

Laura Rechdan Ribeiro Novaes

Virginia Mara Próspero da Cunha

Resumo: O presente estudo objetiva debater a aplicação do projeto Conexão Sustentável, por meio da interação entre três escolas de etapas de ensino diferentes, estimulando e promovendo a sustentabilidade. Para tanto, ocorreu uma ação mútua entre as escolas e etapas educacionais, com tarefas distintas - Escola A (Ensino Fundamental $-5^{\circ}$ ano), Escola $B$ (Ensino Fundamental $-8^{\circ}$ ano) e Escola $C$ ( $3^{a}$ série do Ensino Médio). O Ensino Médio (Escola $C$ ) se encarregou de construir um jogo de tabuleiro, fundamentado na preservação do meio ambiente e a importância da reciclagem. A escola $B$ produziu um vídeo de sensibilização sobre a proteção do planeta, enquanto que, na Escola $A$, os educandos interagiram com as obras produzidas pelas escolas B e C. Após isso, os alunos do $5^{\circ}$ ano da Escola A, escreveram cartas para retornar aos produtores do vídeo e do jogo de tabuleiro o que eles sentiram e acharam sobre os materiais. Como apontamentos finais deste trabalho, percebeu-se que foram estimuladas atitudes de preservação do meio ambiente nos alunos, tanto na hora da participação nas atividades propostas, quanto na pós-execução das mesmas.

Palavras-chave: Educação Ambiental. Sustentabilidade. Meio Ambiente.

Abstract: This study aims to discuss the application of the Sustainable Connection project, through the interaction between three schools of different teaching stages, stimulating and promoting sustainability. For this, there was a mutual action between schools and educational stages, with different tasks - School A (Elementary School 5th year), School B (Elementary School - 8th year) and School C (3rd grade of High School). High School (School C) was in charge of building a board game, based on the preservation of the environment and the importance of recycling. School B produced an awareness video on the protection of the planet, while, at School A, students interacted with the works produced by schools B and C. After that, the 5th year students of School A wrote letters to return to the video and board game producers what they felt and thought about the materials. As final notes of this work, it was noticed that attitudes of preservation of the environment were stimulated in the students, both when participating in the proposed activities and in their post-execution.

Keywords: Environmental Education. Sustainability. Environment.

\section{Introdução}

A educação ambiental é uma forma abarcadora de educação, por meio de um processo pedagógico participativo que procura desenvolver no aluno 
uma consciência crítica sobre os problemas do ambiente e auxiliá-lo a ter uma educação preocupada não somente com o bem estar individual, mas que pense em ideologias que se empenhem na transformação moral da sociedade.

Segundo Magalhães (2015, p. 18) "desperdício de alimentos pode ser considerado como $\mathrm{o}$ ato de eliminação de um alimento potencialmente consumível". Neste contexto, Torrent et al. (2018) destacam que os dados de desperdício de alimentos no mundo são alarmantes, visto que um terço do que é produzido, é jogado fora. "O Brasil é o quarto produtor mundial de alimentos, produzindo $25,7 \%$ a mais do que necessita para alimentar a sua população e o desperdício de alimentos no país chega a 39 mil toneladas por dia" (TORRENT et al., 2018, p. 5).

Observa-se que tal atitude se propaga nos ambientes escolares, espaços propícios para conscientização da importância de práticas mais sustentáveis e a criação de hábitos mais saudáveis e nutritivos nos estudantes.

A alimentação e nutrição adequadas são condições básicas para o crescimento, desenvolvimento e saúde, sobretudo de crianças, considerando ainda que, uma alimentação adequada influencia determinantemente no rendimento escolar, uma vez que favorece a capacidade de concentração do aluno (NASCIMENTO, 2015, p. 08).

Com o objetivo de mapear a presença da Educação Ambiental nas escolas, bem como seus padrões e tendências, através da análise do Censo Escolar entre 2001 e 2004 - realizados pelo Instituto Nacional de Estudos e Pesquisas Educacionais Anísio Teixeira (INEP) e MEC, o Ministério da Educação iniciou o projeto de pesquisa $O$ que fazem as Escolas que dizem que fazem Educação Ambiental? A pesquisa de abordagem quantitativa concluiu que Educação Ambiental nas instituições de ensino fundamental

[...] revela uma realidade preocupante e contraditória com os princípios gerais e participativos da Educação Ambiental, proclamados e consensuados em todos os documentos nacionais e internacionais disponíveis e divulgados nos últimos trinta anos. Com efeito, seja na promoção de uma iniciativa e no envolvimento dos atores que participam do processo, seja na percepção da importância da contribuição dos diversos atores e saberes na compreensão do ambiente, as escolas demonstraram estar distantes da comunidade (HENRIQUES et al., 2007, p. 22, grifo nosso). 
Discutir educação ambiental dentro de sala de aula justifica-se, pois, além de ser um reflexo dos conceitos multiculturais e interdisciplinares, tem se tornado uma necessidade e uma preocupação quanto às soluções que se pretendem para garantir uma melhor qualidade de vida às futuras gerações, possibilitando a perpetuação da vida humana como apontam Santos e Brêtas (2013). O capítulo de introdução do Tratado de Educação para Sociedades Sustentáveis e Responsabilidade Global considera que a

Educação Ambiental para uma sustentabilidade equitativa é um processo de aprendizagem permanente, baseado no respeito a todas as formas de vida. Tal educação afirma valores e ações que contribuem para a transformação humana e social e para a preservação ecológica. Ela estimula a formação de sociedades socialmente justas e ecologicamente equilibradas, que conservam entre si relação de interdependência e diversidade. Isto requer responsabilidade individual e coletiva a nível local, nacional e planetário. Consideramos que a preparação para as mudanças necessárias depende da compreensão coletiva da natureza sistêmica das crises que ameaçam o futuro do planeta (HENRIQUES et al., 2007, p. 103).

Nesse contexto supracitado, a problemática do estudo foi o desperdício de alimentos que acontecia na escola que atende alunos dos anos iniciais do Ensino Fundamental (Escola A). Com base no problema apresentado, foi desenvolvido o projeto Conexão Sustentável que propôs ações síncronas para promover a sustentabilidade entre três escolas diferentes de distintas redes de ensino. As diferentes intervenções foram lideradas, em cada uma das escolas, pelos mestrandos em educação da Universidade de Taubaté que nelas atuam. As mobilizações consistiram na elaboração e aplicação de estratégias que promovessem ações sustentáveis nas referidas escolas. A iniciativa partiu de discussões realizadas na disciplina de Escola, Currículo e Diversidade e tomou forma através de um modelo construído inicialmente pela ferramenta Canvas ${ }^{1}$.

1 O Business Model Canvas ou "Quadro de modelo de negócios" é uma ferramenta de gerenciamento estratégico que permite desenvolver e esboçar modelos de negócio novos ou existentes. É um mapa visual pré-formatado contendo nove blocos do modelo de negócios. 
FIGURA 1 - Modelo CANVAS

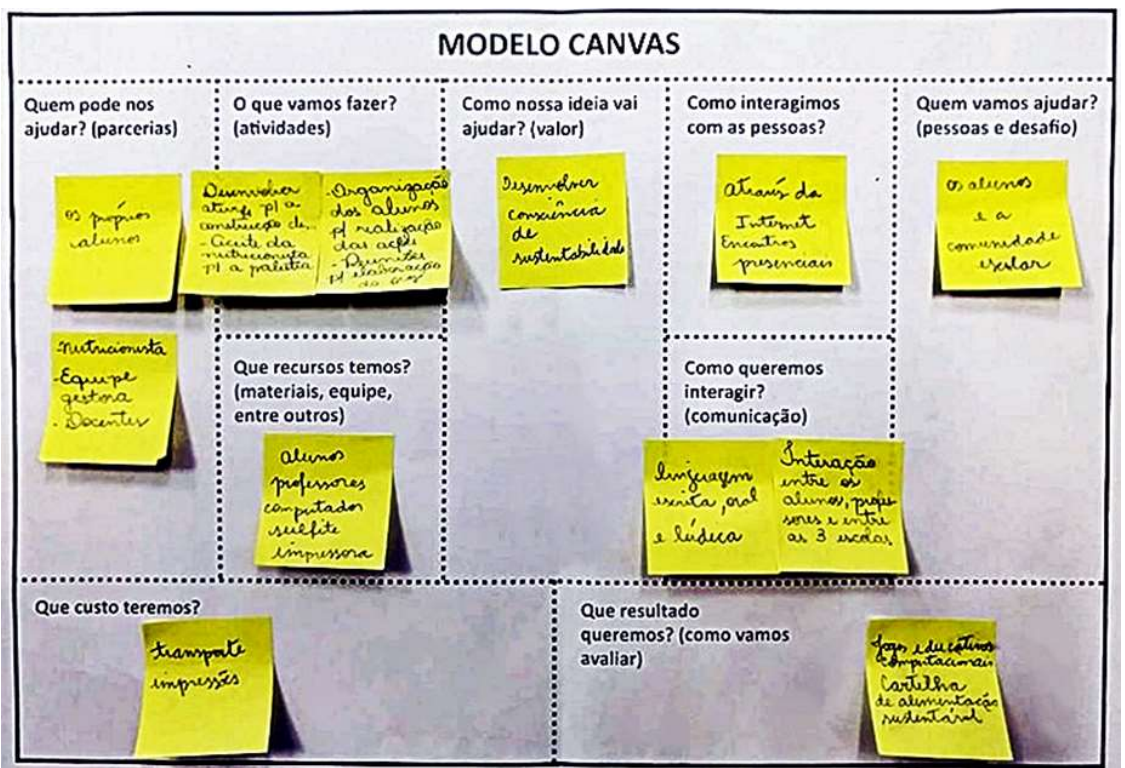

Fonte: Desenvolvido pelos pesquisadores, 2020.

\section{Educação ambiental nas escolas}

É necessário refletir sobre o papel da educação frente aos desafios atuais, sendo a escola um espaço privilegiado para superar e transformar os desafios sociais, econômicos, políticos e culturais, bem como formar indivíduos com senso de responsabilidade.

Uma das ações que se destacam por promover atitudes responsáveis e sustentáveis dentro das escolas, é o Programa Escolas Transformadoras². Este programa enxerga a escola como

espaço privilegiado para proporcionar experiências capazes de formar sujeitos com senso de responsabilidade pelo mundo. Crianças e jovens aptos a assumir papel ativo diante das mudanças necessárias, em diferentes realidades sociais e amparados por valores e ferramentas como a empatia, o trabalho em equipe, a criatividade e o protagonismo (BASSI, 2016, p. 4).

\footnotetext{
2 O programa Escolas Transformadoras é uma iniciativa da Ashoka, a primeira comunidade de empreendedores sociais do mundo. O programa teve início nos Estados Unidos, em 2009, e de lá para cá espalhou-se por 28 países. Hoje conta com uma rede formada por mais de 250 escolas, sendo 15 brasileiras. No Brasil, a iniciativa foi lançada em setembro de 2015 em uma correalização com o Instituto Alana, organização sem fins lucrativos que aposta em projetos que buscam a garantia de condições para a vivência plena da infância.

Fonte: https://escolastransformadoras.com.br/o-programa/sobre/.
} 
A educação ambiental foi implementada nos currículos escolares brasileiros em 2012 e, desde então, passou a fazer parte de todos os níveis educacionais. No ano de 2013, houve o lançamento do Programa Dinheiro Direto na Escola (PDDE) - Escola Sustentável, com a disponibilização de recursos pelo Fundo Nacional de Desenvolvimento da Educação (FNDE) às escolas que tivessem projetos voltados à sustentabilidade.

Para gerar uma cultura pró-sustentabilidade, as escolas se tornam espaços educadores sustentáveis, pois

\begin{abstract}
espaços educadores sustentáveis são aqueles que têm a intencionalidade pedagógica de se constituir em referências concretas de sustentabilidade socioambiental. Isto é, são espaços que contribuem para repensarmos a relação entre os indivíduos e destes com 0 ambiente. Compensam seus impactos com o desenvolvimento de tecnologias apropriadas, permitindo assim, mais qualidade de vida para as gerações presentes e futuras (TRAJBER; SATO, 2000, p. 71).
\end{abstract}

A noção de sustentabilidade cultural aponta para uma nova abordagem interdisciplinar, dedicada a aumentar o significado da cultura e a importância das suas características tangíveis e intangíveis nos campos locais, regionais e globais do desenvolvimento sustentável.

\title{
Educação ambiental: "tá" na lei
}

A aprovação da Lei $n^{0}$ 9.795, de 27.4.1999 e do seu regulamento, o Decreto $n^{\circ}$ 4.281, de 25.6.2002 ${ }^{3}$, estabelecendo a Política Nacional de Educação Ambiental (PNEA), trouxe grande esperança, especialmente para os educadores, ambientalistas e professores, pois, segundo Lipai, Layrargues e Pedro (2007), há muito já se fazia educação ambiental, independentemente de haver ou não um marco legal. Porém, juntamente com o entusiasmo decorrente da aprovação dessas legislações, vieram inevitáveis indagações:

Como elas interferem nas políticas públicas educacionais e ambientais? O direito de todo cidadão brasileiro à educação ambiental poderá ser exigido do poder público e dos

\footnotetext{
3 As leis só passam a ser obrigatórias e exigíveis, após a regulamentação pelo Poder Executivo, o que ocorre por meio dos decretos. Os decretos têm função de explicar os conceitos, competências, atribuições e mecanismos definidos previamente pelas leis, tornandoas executáveis.
} 
estabelecimentos de ensino? Quem fiscaliza e orienta o seu cumprimento? Existe ou deveria existir alguma penalidade para as escolas que não observarem essas legislações? (LIPAl; LAYRARGUES; PEDRO, 2007, p. 24).

A Constituição Federal de 1988 elevou ainda mais o status do direito à educação ambiental, ao mencioná-la como um componente essencial para a qualidade de vida ambiental. Atribui-se, no art. $225, \$ 1^{\circ}$, inciso VI ao Estado o dever de "promover a educação ambiental em todos os níveis de ensino e a conscientização pública para a preservação do meio ambiente" (BRASIL, 1988, p. 131), surgindo, assim, o direito constitucional de todos os cidadãos brasileiros terem acesso à educação ambiental.

Segundo Lipai, Layrargues e Pedro (2007), na Lei de Diretrizes e Bases (LDB), $n^{\circ}$ 9.394/96, que organiza a estruturação dos serviços educacionais e estabelece competências, existem poucas menções à questão ambiental; a referência é feita no artigo 32, inciso II, segundo o qual se exige, para o ensino fundamental, a "compreensão ambiental natural e social do sistema político, da tecnologia, das artes e dos valores em que se fundamenta a sociedade" (BRASIL, 1996, p. 11); e no artigo 36, $\S 1^{\circ}$, segundo o qual os currículos do ensino fundamental e médio "devem abranger, obrigatoriamente, [...] 0 conhecimento do mundo físico e natural e da realidade social e política, especialmente do Brasil" (BRASIL, 1996, p. 12).

Retomando a discussão acerca da Lei $n^{\circ}$ 9.795, de 27.4.1999 que estabeleceu o PNEA, o artigo $9^{\circ}$ avigora os níveis e modalidades da educação formal em que a educação ambiental deve estar presente, apesar de a lei ser clara quanto à sua obrigatoriedade em todos os níveis (ou seja, da educação básica à educação superior) e demais modalidades de ensino (como educação de jovens e adultos, educação a distância e tecnologias educacionais, educação especial, educação escolar indígena e quilombola), englobando também a educação no campo e outras, para garantir a diferentes grupos e faixas etárias o desenvolvimento da cultura e cidadania ambiental.

O artigo $10^{\circ}$ da lei, além de ressaltar a prática integrada da educação ambiental, enfatiza sua natureza interdisciplinar, ao afirmar que "a educação ambiental não deve ser implantada como disciplina específica no currículo de 
ensino" (BRASIL, 1999, p. 5). Porém o $§ 2^{\circ}$ do art. 10 da lei abre exceção à recomendação de interdisciplinaridade facultando a criação de disciplina específica para "os cursos de pós-graduação, extensão e nas áreas voltadas ao aspecto metodológico da educação ambiental, quando se fizer necessário" (BRASIL, 1999, p. 5).

Segundo Lipai, Layrargues e Pedro (2007), o PNEA ainda não resolve o dilema: mas como operacionalizar a educação ambiental incorporando-a ao projeto político-pedagógico e adequando-a à realidade local da comunidade escolar? Porém, ainda segundo os autores, é possível extrair aspectos da educação e da dimensão ambientais que podem ser desenvolvidos em cada nível e modalidade da educação formal, onde o

Órgão Gestor - especificamente o MEC - tem o dever de apoiar a comunidade escolar - professores, estudantes, direção, funcionários, pais e amigos - a se tornarem educadores e educadoras ambientais com uma leitura crítica da realidade, uma leitura da palavra-mundo conforme Paulo Freire (SORRENTINO; TRAJBER, 2007, p. 18, grifo do autor).

Ainda segundo a Lei $n^{\circ}$ 9.795, de 27.4.1999, pode-se concluir que alunos da Educação Infantil e do início do Ensino Fundamental devem desenvolver a sensibilização com a percepção, interação, cuidado e respeito das crianças para com a natureza e cultura destacando a diversidade dessa relação. Alunos dos anos finais do Ensino Fundamental devem ampliar o raciocínio crítico, prospectivo e interpretativo das questões socioambientais bem como a cidadania ambiental. No Ensino Médio e na Educação de Jovens e Adultos, é interessante que os alunos desenvolvam o pensamento crítico, contextualizado e político, e a cidadania ambiental devem ser ainda mais aprofundados, podendo ser incentivada a atuação de grupos não apenas para a melhoria da qualidade de vida, mas especialmente para a busca de justiça socioambiental, frente às desigualdades sociais que expõem grupos sociais economicamente vulneráveis em condições de risco ambiental.

A lei reafirma o direito à educação ambiental a todo cidadão brasileiro comprometendo os sistemas de ensino a provê-lo no âmbito do ensino formal. Segundo Lipai, Layrargues e Pedro (2007), poderíamos dizer que toda(o) 
aluna(o) na escola brasileira tem garantido esse direito, durante todo o seu período de escolaridade.

\section{Sustentabilidade: jovem educa jovem}

A construção da sociedade atual, nos fez caminhar para uma vida de consumo, este consumismo não conectado ao que naturalmente o nosso planeta pode nos oferecer causa danos ao meio ambiente. Trajber (2007) discorre que

quando considerada somente como recurso natural, a natureza, com toda a sua biodiversidade, se transforma em pura mercadoria. Por isso, quando não tem utilidade imediata para o desenvolvimento econômico, florestas, por exemplo, são tratadas como "coisas", que podem ser destruídas, substituídas por espécies mais úteis e desrespeitadas em seu direito de ser e continuar a ser (TRAJBER, 2007, p. 145).

Em uma linha simples de pensamento, produzimos mais que precisamos, temos mais do que usamos, e no fim, lançamos mais resíduos na natureza do que ela pode e consegue absorver. Sendo assim, não respeitamos a biodiversidade da Terra e também a vida dos que aqui habitam.

A discussão sobre sustentabilidade é de extrema necessidade. Trajber (2007) afirma que debater sobre como garantir a qualidade de vida para as gerações futuras, de como integrar o pensamento crítico com maior responsabilidade, por pensar coletivamente é um caminho que devemos propor aos nossos jovens estudantes, para assim, termos um futuro verdadeiramente sustentável.

De fato, a conscientização sobre a importância da conservação do meio ambiente, focado nos nossos jovens, fortificando neles o pensamento de forma coletiva é o caminho para a construção de uma sociedade com qualidade de vida aos seres vivos.

Ao pensar em como podemos construir uma consciência de preservação do meio ambiente na sociedade, enquanto professores, foi a essência do projeto Conexão Sustentável. Dado que "entre jovens a comunicação flui com mais facilidade, e que eles próprios ensinam e aprendem entre si" (DEBONI, 
MELLO, 2007, p. 38), idealizamos os procedimentos do trabalho com a interação entre os alunos das três escolas envolvidas.

Para compreender, inicialmente, os jovens, vamos definir o que é juventude, que segundo Freitas (2005) pode ser desenvolvida por uma série de pontos de partida, como a faixa etária, a período da vida, a categoria social e até mesmo a geração, mas que todas elas vinculam-se "à dimensão de fase do ciclo vital entre a infância e a maturidade" (FREITAS, 2005, p. 6). A autora explica que há uma relação do conceito de juventude com a faixa de idade, que é esta dimensão que dá sentido as análises demográficas.

Pensar na juventude, é ponderar na passagem de criança para adulto, compreende-se assim, que é indispensável garantir a estes indivíduos a oportunidade de que nessa fase de transição tenha as condições necessárias para atingir a maturidade, de fato maduro, preparado a produzir e viver nesta etapa. A autora Abramo (2005) defende que "além dos direitos relativos a formação/preparação para a vida adulta futura [...], é necessário afirmar os direitos dos jovens à inserção [...] e à participação" (ABRAMO, 2005, p. 35, grifo do autor), nesta perspectiva, a educação básica deve promover aos jovens a oportunidade de inserção e à participação nas decisões, incentivando a construção de jovens mais ativos e decisivos na atuação na sociedade.

$\mathrm{Na}$ construção das atividades do projeto "Conexão Sustentável", os alunos participaram ativamente, nas disposições de como e quais ações seriam compartilhadas com os educandos da Escola A, assim, tentamos garantir, aos jovens, a chance de amadurecer o seu pensamento crítico dentro das tomadas de decisões, assim, visando garantir a oportunidade de formação e participação.

\section{A conexão entre as três escolas}

A Escola $A$ envolvida neste estudo atende à Educação Infantil e aos anos iniciais do Ensino Fundamental, com 650 alunos divididos em 37 turmas, a maioria em período integral. A unidade escolar foi inaugurada há pouco mais de cinco anos e, desde então, a alimentação é exclusivamente fornecida pela empresa terceirizada responsável (os alunos não trazem lanche 
externo). A alimentação é baseada em cardápios elaborados por nutricionistas e que variam de acordo com a faixa etária. Busca-se uma alimentação balanceada e saudável. Porém, constatou-se um significativo descarte de alimentos pelos educandos, principalmente as saladas, o que demonstra pouca preocupação com o meio ambiente na vivência dos alunos.

A Lei n 9.795, de 27.4.1999, que estabeleceu o PNEA, define educação ambiental no artigo $1^{\circ}$ como

os processos por meio dos quais o indivíduo e a coletividade constroem valores sociais, conhecimentos, habilidades, atitudes e competências voltadas para a conservação do meio ambiente, bem de uso comum do povo, essencial à sadia qualidade de vida e sua sustentabilidade (BRASIL, 1999, p. 1).

Considerando a importância da educação ambiental, este estudo foi realizado para reverter o quadro observado na escola $A$, conscientizando os alunos acerca da importância de alimentos saudáveis e sem desperdício. Na busca de um espaço educador sustentável, como destaca Bassi (2016), a escola é um lugar privilegiado para desenvolver o discernimento de comprometimento pelo planeta. Deste modo, foi estabelecida uma "Conexão Sustentável", na qual outras unidades escolares foram inseridas nesta ação estratégica.

FIGURA 2 - Relação entre as três escolas

ESCOLA A
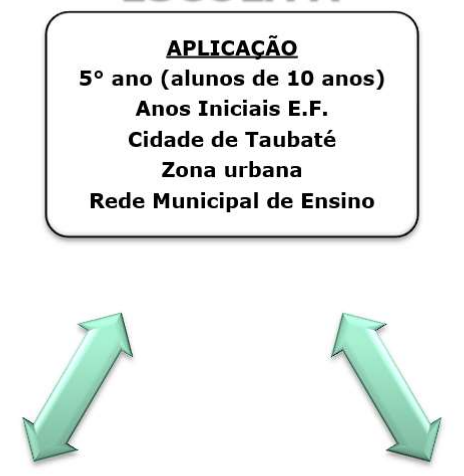

ESCOLA B

ESCOLA C
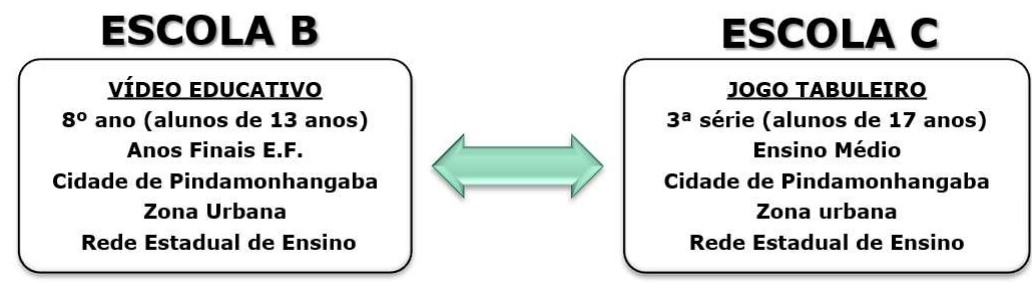

Fonte: Desenvolvido pelos pesquisadores, 2020. 
Portanto, o objetivo deste artigo é debater a aplicação do projeto Conexão Sustentável nos contextos escolares nos quais ele foi desenvolvido e, desta forma, propiciar ao leitor reflexões acerca da sustentabilidade na Educação Básica.

\section{A construção do jogo de tabuleiro (escola c)}

A escola $\mathrm{C}$ atende aos anos finais do Ensino Fundamental e ao Ensino Médio, com 142 alunos divididos em sete turmas, nos períodos matutino e vespertino. Trata-se de uma escola de zona rural. A alimentação é fornecida pela empresa terceirizada responsável e parte é colhida na horta que foi construída através de um projeto interdisciplinar.

Após a apresentação da proposta do projeto "Conexão Sustentável" aos alunos da $3^{\text {a }}$ série do Ensino Médio, eles aceitaram o convite de construir o jogo de tabuleiro imediatamente. A construção iniciou-se a partir de dois encontros com a duração de uma hora e meia cada: o primeiro aconteceu a partir de um brainstorming ${ }^{4}$ colocando as ideias para a construção e regras do tabuleiro, na lousa da sala de aula. Os alunos foram bastante comprometidos e criativos na participação, mediados pelo professor pesquisador. Neste contexto, temos que

Em seu percurso, o estudante conta com o educador, que the orienta em todo o processo [...]. Muitas vezes, os próprios estudantes ensinam. Em grupos colaborativos, ensinam seus colegas sobre determinados assuntos ou aspectos que já compreendem bem. Em projetos específicos, podem contagiar seus colegas com o vivo interesse que demonstram por certos temas e propostas (SINGER, 2017, p.18).

No primeiro encontro, alguns parâmetros foram decididos em conjunto com os alunos:

TÍTULO DO JOGO: Sustentabilidade

TEMAS ABORDADOS:

Reciclagem - Lixo no Lixo

\footnotetext{
${ }^{4}$ técnica utilizada para propor soluções a um problema específico. Consiste em uma reunião também chamada de tempestade de ideias.
} 
Combate à poluição

Combate ao desperdício de alimentos

DURAÇÃO MÉDIA DA PARTIDA:

20 minutos

$N^{\circ}$ DE JOGADORES:

4 alunos e 1 professor supervisor

O segundo encontro aconteceu para a construção do jogo e todos os detalhes e acabamentos. O professor levou todos os materiais para a realização desta etapa do projeto e acompanhou toda a montagem realizada pelos alunos. Em cada detalhe, foi levado em consideração que este jogo seria utilizado por crianças de dez anos de idade.

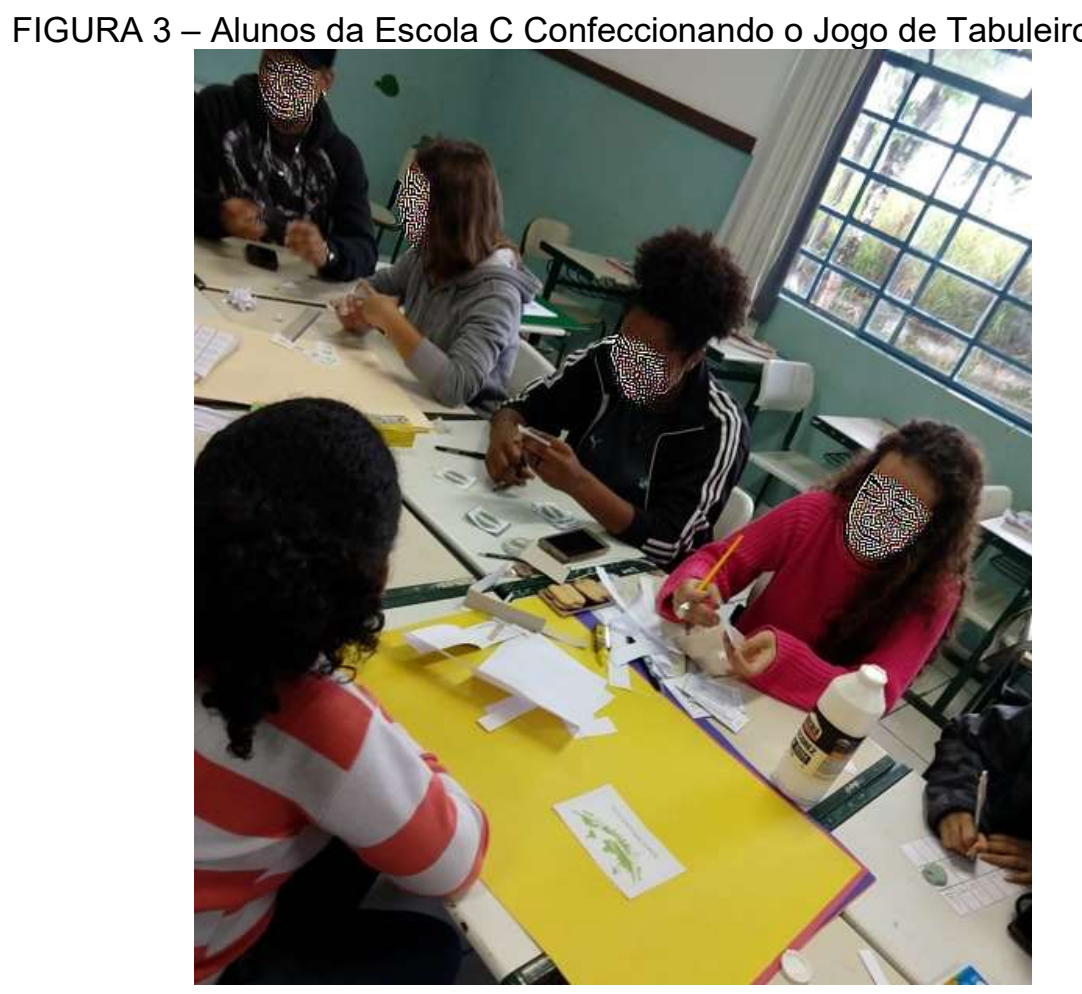

Fonte: Registrado pelos pesquisadores, 2020.

\section{A gravação e edição do vídeo educativo (escola b)}

A escola onde ocorreram as gravações do vídeo está localizada na região central em um município do Vale do Paraíba paulista, da rede estadual de São Paulo, com atendimento do Ensino Fundamental (E.F.) aos anos finais 
e do Ensino Médio (E.M.). No ano da gravação (2019) a escola contava com 18 turmas - dez de E.F. e oito de E.M., totalizando 450 alunos.

Esta etapa do projeto foi construída junto a alunos de três turmas de oitavos anos, sendo que teve o apoio da equipe escolar para realizar a gravação do vídeo. O mestrando, professor efetivo da unidade escolar que lecionava nestas turmas, explicou aos educandos que o projeto consistiria em gravação de vídeo para exposição na escola $A$. Questionou, na sequência, quem gostaria de participar da gravação e, por fim, para a decisão de quem participaria, sorteou três meninas e três meninos.

Para o uso das imagens dos jovens na gravação, foi previamente exposta aos pais a proposta do projeto e, pós-consentimento dos responsáveis, deu-se a continuidade do trabalho. O número de estudantes escolhidos para a gravação deve-se ao tempo de vídeo definido entre os pesquisadores anteriormente, que era de no máximo dez minutos, pois partimos do princípio que para ter atenção dos espectadores, precisávamos de uma apresentação não extensa.

Neste primeiro momento, não foi dada a informação sobre a temática do trabalho. A escolha de não contar aos estudantes sobre o tema do trabalho se deu ao fato de que eles iriam ver três imagens - retiradas do Google Imagens e a gravação tinha a função de captar as reações deles às situações que foram retratadas nas fotos; talvez se o docente explicasse antes, o ideário do vídeo pudesse ser deturpado. Em uma realidade onde os alunos

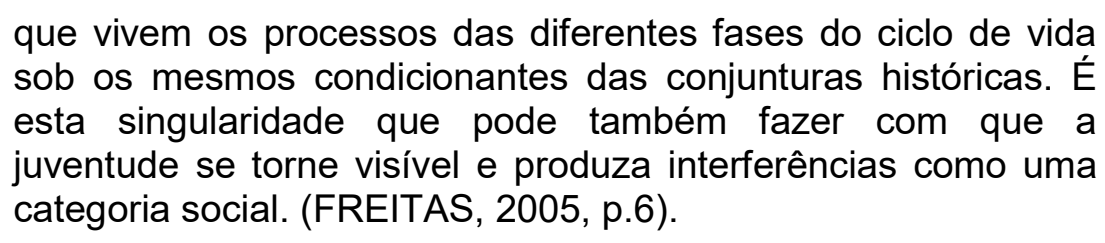

As imagens escolhidas para a reação dos alunos consistiam em situações de desperdício de comida, rios poluídos e crianças em situação de risco em razão da poluição de água. A intenção de colocá-los nesta posição, era justamente de ligá-los emocionalmente aos telespectadores. Assim, a comunicação, mesmo que não por contato direto entre os alunos das duas escolas, teria uma aproximação e intimidade, logo, a mensagem a ser 
transmitida pelo vídeo, sobre a importância de preservar o meio ambiente, poderia ter um impacto mais efetivo.

A gravação foi realizada dentro da escola, com a auxílio da Coordenadora Pedagógica. Os alunos, um por vez, visualizaram as imagens em uma sala onde estava apenas o professor, para não ter interferência externa. Os alunos que viam as imagens não tinham contato com os alunos que ainda a veriam, pra não ocorrer especulação do que aconteceu. Além das imagens, aos educandos foi feita uma pergunta e um pedido. Primeiro, "o que você entende por sustentabilidade?', e, após o vídeo, deixar "uma sugestão para os alunos que verão o vídeo.". Esta etapa durou quase uma hora.

Com os vídeos das reações dos alunos, foi realizada a primeira edição, para juntar os vídeos, recortar para enquadrar as imagens, corrigir o áudio e também inserir o logo do projeto. Este processo durou em média 2 horas, não consecutivas.

Com a primeira edição, o professor mestrando debateu com os alunos para construírem a mensagem que o vídeo iria transmitir. Para isso, foi utilizado o recurso de time-lapse (câmera-rápida) para capturar a mão de uma aluna desenhando e construindo a narrativa da história do vídeo, inclusive com a adição no final do vídeo do pedido aos espectadores para encaminhar uma carta aos alunos que participaram da gravação. Esta etapa durou uma hora e trinta minutos.

A segunda edição foi realizada para juntar o time-lapse com os vídeos dos alunos. Após esta junção, o vídeo voltou para os alunos dos oitavos anos para a realização da narração e, por fim, foi realizada a junção deste áudio com o vídeo editado. Este procedimento durou 2 horas não consecutivas.

Para a edição do vídeo foi utilizado o aplicativo Movavi VideoEditor 14, em computador com sistema operacional Windows 10.

Após a finalização, o vídeo foi transmitido aos participantes da gravação para avaliação deles. Os alunos do oitavo ano mostraram-se mais tímidos ao se verem do que no ato da gravação do vídeo. Curiosidade deste momento foi o pedido, quase que unânime, de não transmitir as imagens para os colegas da escola deles. 
Finalizada a gravação, edição e verificação dos alunos, o vídeo foi encaminhado para aplicação na Escola A.

\section{A aplicação na escola (escola a)}

Após a constatação do desperdício de alimentos na Escola $A$, problema inicial deste relato, algumas ações foram desenvolvidas na unidade escolar enquanto as Escolas B e C faziam o vídeo e o jogo de tabuleiro, respectivamente.

Em parceria com a Secretaria de Educação do município e estagiárias de uma faculdade de Nutrição, foi realizada avaliação nutricional com os alunos da unidade escolar, como também orientações para os educandos quanto à alimentação saudável e ao desperdício de alimentos.

Oportunamente, para trabalhar com os referidos temas, os alunos do Integral prepararam um teatro com o título "De Olho na Balança", uma espécie de programa de entrevista em que abordaram assuntos pertinentes às temáticas.

Em conjunto com a Secretaria do Meio Ambiente, também foi feita uma horta na escola A. Profissionais habilitados trabalharam a terra e alunos plantaram as mudas. "A experiência na horta restabelece a conexão das crianças com os fundamentos da alimentação e, ao mesmo tempo em que integra, torna-as mais interessadas nas outras atividades da escola". (CAPRA, 2008 apud SANTOS; GARDOLINSKI, 2016, p. 11).

$O$ vídeo produzido na escola $B$ foi enviado à escola $A$ e assistido pelos alunos do período integral, para os quais a experiência foi muito satisfatória. O assunto foi discutido pelas crianças e, em pequenos grupos, fizeram cartas para os estudantes que produziram o vídeo. Os educandos também tiveram a oportunidade de brincar com o jogo de tabuleiro produzido pelos alunos do Ensino Médio da Escola C. De forma lúdica, vivenciaram os conceitos importantes da sustentabilidade, refletindo sobre as questões abordadas. Na interação entre as escolas, Singer (2017) evidencia que

As diferenças enriquecem os projetos e os estudos e estimulam a interação construtiva e cuidadosa. O convívio com 
pessoas de outras idades, gêneros e culturas possibilitado pela integração dos diferentes espaços, tempos e atores leva os estudantes a se interessar pelo outro, por suas experiências, preferências e culturas. Esse vivo interesse pelo diferente é aspecto central do desenvolvimento social dos indivíduos. (SINGER, 2017, p.19).

Percebe-se que a unidade escolar se tornou um espaço de aprendizagem ambiental, no qual foram estabelecidas diferentes redes relacionais voltadas à conscientização e à formação integral de todos os alunos, proporcionando situações e hábitos que possam ser adquiridos e vivenciados por toda a comunidade escolar em busca de um planeta sustentável.

FIGURA 4 - Alunos da Escola A Interagindo com Jogo

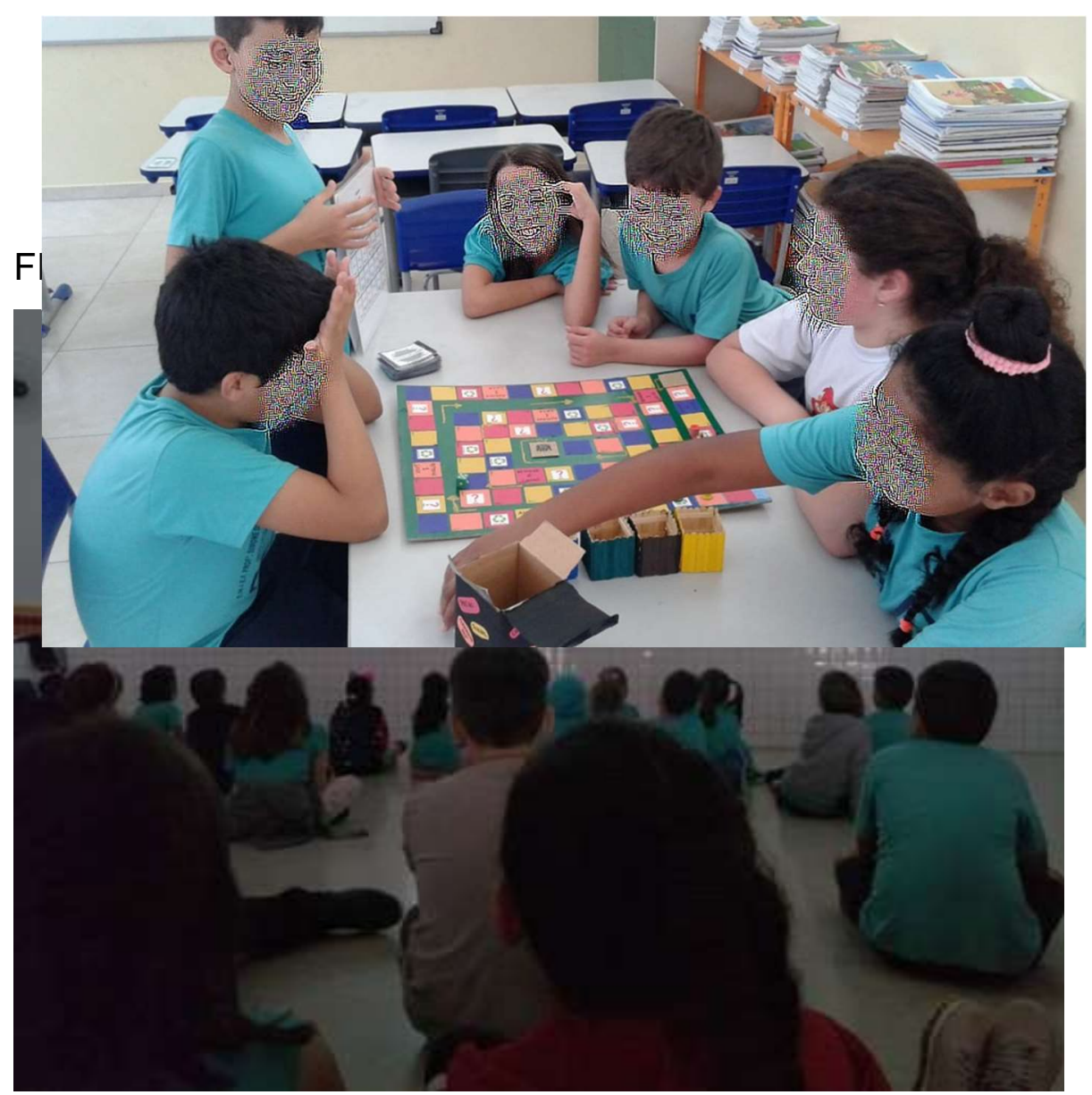

Fonte: Registrado pelos pesquisadores, 2020. 


\section{Resultados}

A Escola A oferece três tipos de cardápio para os educandos: $O$ Cardápio I (crianças do berçário de até 1 ano de idade), o Cardápio II (crianças da Educação Infantil) e o Cardápio III (alunos dos anos iniciais do Ensino Fundamental); e o consumo diário de alimentos em todas as refeições está em torno de 300 quilogramas de alimentos por dia, dentre refeições molhadas e secas.

Anteriormente ao projeto, através da medição por meio da pesagem dos restos de comida desperdiçados girava em torno de 30 quilogramas por dia e, após a aplicação e desenvolvimento das ações propostas, o desperdício caiu para uma média 28,5 quilogramas. Percebe-se, portanto, uma diminuição de cerca de $5 \%$ na quantidade de sobras da alimentação diária desta escola, lembrando que o projeto foi aplicado apenas nos quintos anos.

A partir da observação da pesquisadora e dos relatos advindos dos demais docentes desta escola, percebeu-se que com as ações educativas propostas pelo projeto "Conexão Sustentável", foram notados a partir da fala e atitudes dos alunos, uma maior cidadania, uma consciência ambiental mais apurada e maior responsabilidade no consumo de alimentos. Além, é claro, da constatação da redução do desperdício de alimentos, problema central que motivou o desenvolvimento do projeto,

Contudo, toda a equipe envolvida na Escola $A$, reconhece a necessidade de ampliação deste projeto. Assim sendo, pretende-se continuar com a proposta junto aos demais anos iniciais do Ensino Fundamental, a fim de que a diminuição do desperdício dos alimentos ocorra de forma ainda mais efetiva nesta mesma escola e, também, na comunidade na qual se insere. A proposta é tornar os educandos agentes multiplicadores das ações de conscientização em suas famílias.

\section{Apontamentos finais}

As escolas são espaços propícios para o diálogo e para práticas sociais sustentáveis. Assim sendo, este trabalho foi de grande valia como motivador de atitudes mais conscientes aos alunos das três unidades escolares envolvidas, 
como forma de conscientização e responsabilização de todos os atores do processo educativo (estudantes, educadores, comunidade etc.) em busca de um bem comum.

Com as atividades desenvolvidas, foi possível perceber uma mudança nas ações e costumes dos educandos da Escola $A$, os quais passaram a se alimentar de forma mais consciente, diminuindo o desperdício anteriormente observado. Percebe-se que com a conscientização e a transformação dos indivíduos foi possível também a modificação de práticas coletivas. Guimarães (2007) explica o que é necessário para a construção de práticas transformadoras de uma sociedade sustentável:

Para tanto é desejável a criação, por nós educadores, de um ambiente educativo que propicie a oportunidade de conhecer, sentir, experimentar; ou seja, vivenciar aspectos outros aos que predominam na constituição da atual realidade socioambiental. Isso poderá potencializar uma prática diferenciada que, pelo incentivo à ação cidadã em sua dimensão política, repercuta em novas práticas sociais voltadas para a sustentabilidade socioambiental (GUIMARÃES, 2007, p. 91).

Ao assumir uma postura problematizadora da realidade socioambiental, os educadores possibilitaram o desenvolvimento do senso crítico e a mudança de comportamento dos alunos, os quais se tornaram multiplicadores dos debates e ideias em suas famílias e comunidades, possibilitando a participação cidadã e crítica de todos os envolvidos e a construção de uma sociedade efetivamente sustentável.

\section{Referências}

BRASIL. Constituição Federal de 1988. Promulgada em 5 de outubro de 1988.

Disponível em https://www2.senado.leg.br/bdsf/bitstream/handle/id/518231/CF88_Livro_EC91 _2016.pdf. Acesso em: 01 dez. 2019.

BRASIL. Lei $n^{\circ}$ 9.795, de 27 de abril de 1999: Dispõe sobre a educação ambiental, institui a Política Nacional de Educação Ambiental e dá outras providências. Disponível em: http://www.planalto.gov.br/ccivil_03/leis/19795.htm. Acesso em: 01 dez. 2019. 
BRASIL. Lei de Diretrizes e Bases. Lei $n^{\circ} 9.394$ de 1996. Disponível em http://portal.mec.gov.br/seesp/arquivos/pdf/lei9394_Idbn1.pdf . Acesso em: 01 dez. 2019.

DEBONI, Fábio; MELO, Soraia Silva de. Pensando Sobre a "Geração do Futuro" no presente: jovem educa jovem, Com-vidas e conferência. In: MELLO, Soraia Silva de; TRAJBER, Rachel (Org.). Vamos cuidar do Brasil: conceitos e práticas em educação ambiental na escola. Brasília: Ministério da Educação, Coordenação Geral de Educação Ambiental: Ministério do Meio Ambiente, Departamento de Educação Ambiental: UNESCO, 2007. cap. 1, p. 35-44.

BASSI, Flávio. A Importância da Empatia na Educação. 2016. Elaborado pela organização mundial Ashoka. Disponível em: https://escolastransformadoras.com.br/wpcontent/uploads/2016/11/PUBLICACAO_EMPATIA_v6_dupla.pdf. Acesso em: 30 set. 2020.

FREITAS, Maria Virginia de. Introdução. In: FREITAS, Maria Virginia de (Org.). Juventude e Adolescência no Brasil: referências conceituais. São Paulo: Ação Educativa, 2005. cap. 1, p. 6. Disponível em: https://library.fes.de/pdffiles/bueros/brasilien/05623.pdf

GUIMARÃES, Mauro. Educação Ambiental: participação para além dos muros da escola. In: MELLO, Soraia Silva de; TRAJBER, Rachel (Org.). Vamos cuidar do Brasil: conceitos e práticas em educação ambiental na escola. Brasília: Ministério da Educação, Coordenação Geral de Educação Ambiental: Ministério do Meio Ambiente, Departamento de Educação Ambiental: UNESCO, 2007. cap. 2, p. 85-94.

HENRIQUES, Ricardo; TRAJBER, Rachel; MELLO, Soraia; LIPAI, Eneira Markawa; CHAMUSCA, Adelaide. Educação Ambiental: aprendizes de sustentabilidade. Brasília: MEC, 2007.

LIPAI, Eneida Maekawa; LAYRARGUES, Philippe Pomier; PEDRO, Viviane Vazzi. Educação Ambiental na Escola: tá na lei. In: MELLO, Soraia Silva de; TRAJBER, Rachel (Org.). Vamos cuidar do Brasil: conceitos e práticas em educação ambiental na escola. Brasília: Ministério da Educação, Coordenação Geral de Educação Ambiental: Ministério do Meio Ambiente, Departamento de Educação Ambiental: UNESCO, 2007. cap. 1, p. 23-34.

NASCIMENTO, Maria Celeste Passos Silva. Alimentação escolar em três escolas públicas no município de Itapetinga BA: uma contribuição para educação ambiental - Itapetinga: UESB, 2015. 67f.

SANTOS, Suzana Peres dos; GARDOLINSKI, Maria Terezinha Hanel Antoniazzi. A importância da educação ambiental nas escolas para a construção de uma sociedade sustentável. 2016. Disponível em: http://www2.al.rs.gov.br/biblioteca/LinkClick.aspx?fileticket=1VmNggPU170\%3

D\&tabid. Acesso em: 28 ago. 2019. 
SINGER, Helena. Pelo protagonismo de estudantes, educadores e escolas. In: LOVATO, Antonio; YIRULA, Carolina Prestes; FRANZIM, Raquel (Org.). Protagonismo: a potência de ação da comunidade escolar. São Paulo: ASHOKA, ALANA, 2017. cap. 1, p. 14-21.

SORRENTINO, Marcos; TRAJBER, Rachel. Políticas de Educação Ambiental do Órgão Gestor. In: MELLO, Soraia Silva de; TRAJBER, Rachel (Org.). Vamos cuidar do Brasil: conceitos e práticas em educação ambiental na escola. Brasília: Ministério da Educação, Coordenação Geral de Educação Ambiental: Ministério do Meio Ambiente, Departamento de Educação Ambiental: UNESCO, 2007. cap. 1, p. 13-22.

TORRENT, Isadora Froes et al. Desperdício de Alimentos no Ambiente Escolar. Revista Espacios. Vol. 39 (№ 48) Ano 2018.

TRAJBER, Rachel. Cidadania e Consumo Sustentável: nossas escolhas em ações conjuntas. In: MELLO, Soraia Silva de; TRAJBER, Rachel (Org.). Vamos cuidar do Brasil: conceitos e práticas em educação ambiental na escola. Brasília: Ministério da Educação, Coordenação Geral de Educação Ambiental: Ministério do Meio Ambiente, Departamento de Educação Ambiental: UNESCO, 2007. cap. 2, p. 143-152.

TRAJBER, Rachel; SATO, Michèle. Escolas Sustentáveis: incubadora de transformações nas comunidades. Revista Eletrônica do Mestrado em Educação Ambiental. Rio Grande, v. especial, n. 3, p. 70-78, set. 2000.

\section{Sobre os Autores}

\section{Danilo Garufe Gomes}

danilogarufe@gmail.com

Graduou-se em Matemática com habilitação em Física pela Universidade de Taubaté (Licenciatura 2012), onde também realizou sua especialização em Docência da Matemática (2015) e está cursando seu mestrado profissional em educação com conclusão prevista para 2021. Atua como professor de educação básica na rede pública estadual paulista e no Serviço Nacional de Aprendizagem Comercial - SENAC.

\section{Ana Maria Gimenes Corrêa Calil}

ana.calil@unitau.br

Doutora em Educação (Psicologia da Educação) pela Pontifícia Universidade Católica de São Paulo PUC-SP (2014), Mestre em Educação (Psicologia da Educação) pela Pontifícia Universidade Católica de São Paulo PUC-SP e graduada em Economia e Pedagogia pela Universidade de Taubaté. Atualmente sou professora de Metodologia do Ensino da Educação Infantil e Anos iniciais do Ensino Fundamental e coordenadora do Departamento de Pedagogia da Universidade de Taubaté, professora e coordenadora do Mestrado Profissional em Educação da mesma universidade. 


\section{Antonio Rodolfo Souza da Silva}

antonio_rodolfo@msn.com

Possui curso técnico-profissionalizante pela ETEC João Gomes de Araújo (2006). Atualmente é Professor Coordenador Geral da E.E. Dr. João Pedro Cardoso e Pesquisador da Universidade de Taubaté. Tem experiência na área de Matemática. Atuando principalmente nos seguintes temas: Educação a Distância, Egresso, Desenvolvimento Profissional Docente

\section{Juliana Marcondes Bussolotti}

julianabussolotti@gmail.com

Possui graduação em Escola de Comunicação e Artes pela Universidade de São Paulo, pós-graduação lato sensu em Designer Instrucional pela Universidade Federal de Itajubá, mestrado em Ciências Ambientais pela Universidade de Taubaté e doutorado em Geografia pela Universidade Estadual Paulista. Atualmente é pesquisadora da Universidade Estadual Paulista (pós-doc Programa de Pós-Graduação em Desenvolvimento Territorial na América Latina e Caribe - TerritoriAL). Professora assistente III da Universidade de Taubaté, professora coordenadora adjunta do Mestrado Profissional em Educação da Universidade de Taubaté

\section{Laura Rechdan Ribeiro Novaes}

1rechdan@hotmail.com

Graduada em Letras (2013) e em Pedagogia (2002). Possui as seguintes especializações: Psicopedagogia, Educação Especial, Gestão do Trabalho Pedagógico, Educação Infantil e Direito Educacional. Atualmente é professora I - diretora de escola da Prefeitura Municipal de Taubaté. Tem experiência na área de Educação, com ênfase em Administração de Unidades Educativas.

\section{Virginia Mara Próspero da Cunha}

vimaracunha@terra.com.br

Possui graduação em Licenciatura em Educação Física pela Universidade de Taubaté (1986), graduação em Licenciatura em Pedagogia, habilitação em Administração Escolar, pela Universidade de Taubaté (1989), graduação em Licenciatura em Pedagogia, habilitação em Magistério, pela Faculdade de Educação de Guaratinguetá (1996), MESTRADO em Educação: Psicologia da Educação, pela Pontifícia Universidade Católica de São Paulo (2003) e DOUTORADO em Educação: Psicologia da Educação, na Pontifícia Universidade Católica de São Paulo (2009). É PROFESSORA ASSISTENTE III, efetiva, titular da disciplina: EDUCAÇÃO FÍSICA ESCOLAR, da UNIVERSIDADE DE TAUBATÉ - SP 